\title{
Circulação de informação econômica, companhias de seguros e a formação de instituições no Brasil
}

\author{
Circulation of economic information, insurance companies \\ and the formation of institutions in Brazil
}

\author{
BEATRIZ DUARTE LANNA \\ Universidade Estadual de Campinas | UNICAMP
}

\begin{abstract}
RESUMO Este artigo busca apresentar a importância da circulação de informação econômica para o funcionamento das companhias de seguro no Brasil do final do século XIX e início do XX. Sem o auxílio da sistematização de dados ou de um arsenal técnico sofisticado o suficiente para que precificassem os riscos de suas apólices, essas firmas utilizaram-se do espaço público da imprensa para divulgarem informações econômicas a respeito de seu funcionamento, bem como para se informar acerca da situação de suas firmas concorrentes. A publicação de dados econômicos nos jornais tornou-se, portanto, uma ferramenta de atuação dessas companhias, a partir da qual se consolidam como instituições.
\end{abstract}

Palavras-chave circulação de informações econômicas - companhias de seguros - imprensa

\begin{abstract}
This article seeks to present the importance of the circulation of economic information for the operation of insurance companies in Brazil at the turn of the twentieth century. Without the help of data systematization or a technical arsenal sophisticated enough to price the risks of their policies, these firms used the public space of the press to disseminate economic information about their operations, as well as to acquire information about the situation of competitors. The publication of economic data in newspapers therefore became a tool for the performance of these companies, a tool they used in order to consolidate themselves as institutions.
\end{abstract}

Keywords circulation of economic information - insurance companies - press

\section{Introdução}

0 presente texto busca apresentar a importância da sistematização de informações, bem como sua publicação na imprensa, para o funcionamento das companhias de seguros no Brasil do final do século XIX e início do XX, momento em que as seguradoras ganham razoável inserção na economia brasileira. Sabemos que ao longo do século XX a estatística tornou-se uma ferramenta fundamental para o funcionamento dessas firmas, que passam a basear grande parte de sua atuação nas informações obtidas a respeito de acidentes, probabilidades de sinistros, hábitos de consumo e condições materiais de existência. As características gerais do contrato de seguro moderno se fazem a partir de um grande volume de informações coordenadas, que incluem desde avaliações contínuas de riscos, sua mensuração e administração, até cálculos dos prêmios e das reservas necessárias para a liquidez e solvência das firmas. A racionalidade quantificadora do Estado e das empresas atua no sentido de calcular eventualidades e contingências, e se aperfeiçoa conforme o faz. 
Para casos específicos do final do século XIX e início do XX, as possibilidades de organização e coordenação de informações eram naturalmente mais restritas. Mensurar e administrar riscos, analisar eventos e caracterizá-los como vulneráveis eram tarefas feitas de maneira rudimentar, muito distantes do formato adotado pelas firmas contemporâneas, cuja atuação baseia-se na análise de sofisticados modelos estatísticos que levam em consideração uma ampla gama de variáveis. Para o caso brasileiro, podemos considerar que a estatística torna-se uma ferramenta de normalização das expectativas e base para a construção de políticas públicas ao longo da primeira metade do século XX, sobretudo após as décadas de 1910 e 1920; a partir de então a análise pragmática da população, vista agora como um campo autônomo que pode ser regulado, funcionará como referência à ação do Estado. Antes das referidas décadas, no entanto, notamos expressiva ausência de inferências estatísticas no discurso político e nos quadros programáticos dos governos. ${ }^{1}$

A utilização da estatística por parte das seguradoras consolida-se apenas a partir da segunda metade do século $X X$, quando se torna instrumento de gestão do risco social das companhias. As práticas de cálculo contábil adotadas servirão não apenas para avaliar oportunidades particulares de investimento, mas também para aumentar o padrão geral de eficiência das firmas e melhorar suas tomadas de decisões.?

Outros trabalhos trataram a respeito da relação entre companhias de seguros e práticas contábeis para mensuração de riscos, apresentando as noções de sinistro, segurança, seguridade e seguro como remetentes a uma forma de pensar especifica e ocidental. Com a consolidação desta forma de pensar na estrutura das firmas, estabeleceu-se a percepção de que determinados eventos são passiveis de quantificação, e confluiu-se desde aí o papel das seguradoras, da estatística e das ciência atuariais. Ao serem aplicadas a casos concretos, a atuária e a contabilidade permitem que as companhias evidenciem em seus balanços as obrigações para com seus segurados via provisões técnicas, isto é, formulações matemáticas que vislumbram sinistros. É o confronto entre o prêmio pago pelos segurados e o sinistro gasto pelas seguradoras que permitirá a apuração de lucros ou prejuízos por parte destas firmas. ${ }^{4}$

Se eventos considerados incertos serão coletados e mensurados, formar-se-á uma compreensão estatística e demográfica dos fenômenos humanos. A partir daí será possível pensar não apenas na probabilidade de o risco de fato ocorrer, mas também nas condições para sua formação. 0 risco será considerado um modo especifico de lidar com determinados eventos, possíveis de afetar indivíduos ou grupos societários maiores; para de fato captá-lo faz-se necessária sua contínua inserção em determinados contextos, eventos e conjunturas. . $^{5}$ As companhias seguradoras teriam então o papel de rearranjar e ordenar os elementos da realidade considerados incertos, fazendo-o a partir de seus próprios cálculos de probabilidade. $\underline{6}$

Considerando a impossibilidade das companhias de seguros no Brasil do final do século XIX e início do XX utilizarem-se do conhecimento estatístico para precificarem os riscos das apólices, temos que estas firmas empregavam outras ferramentas para se estabelecerem de maneira sólida no mercado de seguros, incipiente e ainda em ascensão. Preocupadas com sua imagem frente a um público pouco familiarizado com a ideia do seguro, estas companhias utilizaram-se da circulação de informação econômica, bem como sua publicação em periódicos e meios de comunicação, para conquistarem a confiança do mercado local. Apresentaremos alguns exemplos empíricos da auto representação dessas firmas, além dos ataques recíprocos que realizaram contra suas companhias concorrentes, sempre via imprensa, ao final do século XIX e início do XX.

Consideraremos que 0 acesso à informação econômica e sua divulgação pública contribuíram para que as companhias de seguros se constituíssem como importante inovação institucional no Brasil desse período. Este acesso à informação se deu sobretudo a partir da divulgação de estatutos e balanços em importantes periódicos e outros meios de circulação da imprensa; a divulgação de dados econômicos nos jornais fazia parte do modus-operandi das firmas seguradoras nesse momento. Além disso, trataremos a respeito das mudanças regulatórias na legislação do setor seguros, fundamentais para que estas companhias pudessem de fato realizar análises de risco, quantificações e avaliações de clientes. Novamente, reiteramos que para o caso do século XIX todas estas possibilidades estiveram muito mais restritas do que as precificações possíveis de serem feitas a partir do arsenal técnico do século XX. 


\section{As companhias de seguros como instituições}

Considerando, portanto, que o uso do conhecimento estatístico por parte das companhias de seguros está estreitamente relacionado ao papel que desempenham como instituições, temos que estas últimas são determinantes para o funcionamento da economia capitalista por permitirem a redução dos custos de transação e o aumento dos ganhos de produtividade. ${ }^{?}$ Ao lado de outros arranjos institucionais, como a formação de economias de escala via a atuação de grandes empresas e o incentivo à inovação e à formação de patentes, a construção de companhias de seguros é tida pela bibliografia clássica como um exemplo de instituição capaz de reduzir as imperfeições do mercado. $\underline{\text { }}$

Nesse sentido, a existência de um sistema de quantificação e de dispositivos estatísticos capazes de alimentar os bancos de dados das companhias de seguros também se constitui como uma instituição, novamente no sentido proposto por Douglass North, a saber, um sistema capaz de compor as "regras do jogo de uma sociedade".. A atuação desse corpo de dados ajudaria a reduzir o grau de incerteza das interações econômicas e estimularia um adequado ambiente às trocas.

Para além da compilação de dados estatísticos, é importante que as companhias de seguros possam divulgar publicamente a informação econômica acerca de seu próprio funcionamento, cuja absorção pelos consumidores pode ter efeitos diretos sobre a atuação das firmas. A publicação de indicadores de produção de seguradoras em jornais e revistas já era uma realidade no final do século XIX e início do XX, momento em que, como afirmamos, as possibilidades de manejo do conhecimento estatístico eram muito restritas. A sistemática publicação de dados influenciou na construção da imagem dessas companhias, que se utilizavam da divulgação positiva de seus respectivos indicadores de produção para se promover. A situação contrária também era verdadeira; seguradoras rivais divulgavam dados negativos acerca de suas concorrentes em busca de um melhor posicionamento no mercado. Também eram divulgados na imprensa casos específicos de fraudes, na maior parte das vezes envolvendo tentativas para forjar sinistros ou obter prêmios de maneira indevida.

Cabe aqui chamarmos atenção ao fato de que o conceito de instituição não se refere apenas a uma organização ou estabelecimento capaz de promover um objetivo particular, como um banco comercial, um Banco Central, ou mesmo uma companhia de seguro. 0 ponto de vista institucionalista apresenta o conceito de "instituição" como um padrão organizado ou um comportamento grupal; isso pode incluir hábitos, leis, modos de pensar, costumes e estruturas societárias, desde que bem estabelecidos e aceitos como parte fundamental da cultura. A vida econômica seria, portanto, regulada por estas instituições, e não por supostas leis econômicas imutáveis..$^{10}$

A perspectiva estática da teoria neoclássica, que reivindica modelos de equilíbrio para interpretar realidades dinâmicas, acaba por deixar de lado grande parte da complexidade dos processos econômicos, cujas nuances não são captadas pelos modelos. 0 olhar institucionalista, ao contrário, ofereceria um ponto de vista mais amplo e dinâmico, capaz de, através de sua própria teoria, incorporar a perspectiva da mudança e do movimento. Para a análise da formação e atuação de estruturas reguladoras da sociedade como as companhias de seguros, este olhar mostra-se bastante profícuo, pois parte-se do pressuposto de que a sociedade e as instituições estão em constante transformação. ${ }^{11}$

\section{A legislação reguladora das companhias de seguros}

Antes de apresentarmos exemplos empíricos de divulgação de informação econômica pelas companhias de seguros na imprensa, cabe aqui realizarmos uma breve reconstituição da atuação dessas firmas no Brasil e da sua legislação reguladora. As primeiras seguradoras aqui formadas datam do período de chegada da corte portuguesa ao Rio de Janeiro em 1808, momento de forte participação do capital mercantil e das atividades comerciais. Para esse período, a abertura das companhias de seguros cumpria com o papel de fornecer maior segurança econômica e estimular a expansão 
do comércio marítimo local. Eram empresas formadas por grupos locais e voltadas ao atendimento das demandas de seguro do comércio marítimo, respondendo ao típico perfil dos empreendimentos que seriam formados até meados do século XIX. Esta situação condiz com o perfil essencialmente exportador da economia brasileira da época, cujos grupos mercantis exportadores e importadores respondiam por parte significativa da renda nacional.

Ao longo do século XIX, durante o processo de formação do Estado brasileiro e de crescimento da economia imperial, assistiu-se à expansão do número de empresas de seguros nacionais e ao início da entrada das primeiras firmas estrangeiras, que chegam sobretudo a partir da década de $1860.12 \mathrm{As}$ companhias de seguros que se instalaram no Brasil estabeleceram suas atividades junto às empresas de comércio marítimo, de importação e companhias de navegação. Na origem, as sociedades aqui estabelecidas ou construídas respondiam ao caráter mercantil da economia brasileira: buscavam assegurar garantias ao transporte marítimo, reproduzindo as regulamentações e as experiências das pioneiras empresas europeias. ${ }^{13}$ Com a diversificação do perfil de apólices atendidas - que ao longo do tempo deixam de se relacionar apenas às transações marítimas e voltam-se também ao comércio terrestre, ao seguro de vida, contra incêndio e até mesmo de escravos c e também com a ampliação de sua área de atuação por meio de agências - as companhias alcançaram um crescente número de Províncias; tem-se que a prioridade do negócio, até fins do século XIX, era de fomentar o comércio nacional e dar mais garantias ao seu funcionamento.

Foram os marcos na legislação reguladora do setor de seguros que permitiram um maior acesso à informação por parte das firmas, e, por conseguinte, uma melhor inserção e atuação destas últimas no mercado brasileiro, ainda em formação. Conforme a legislação para o setor era construída, as companhias passavam a ter maior acesso a dados, informações e sistematizações a respeito do próprio campo em que estavam inseridas.

0 primeiro marco para a legislação específica foi a promulgação do Código Comercial de 1850, importante mudança institucional cujos efeitos fizeram-se sentir de maneira evidente. Até o início do funcionamento do Código, as companhias de seguros brasileiras funcionavam sobretudo a partir de instituições portuguesas, ou, em casos específicos, de legislação estrangeira referente às sedes das seguradoras vindas de fora. A partir de sua promulgação, legislou-se pela primeira vez em torno do funcionamento das companhias de seguros; mais do que isso, tornou-se possível compilar dados básicos a respeito do funcionamento dessas firmas no que diz respeito a aberturas e fechamentos, quebras e falências, possibilidades de inserção produtiva, dentre outras informações. A partir das definições que o Código apresentava em torno do transporte e do comércio, estipulando regras e acordos, as companhias de seguros puderam se inserir com mais segurança em um mercado em plena construção. ${ }^{14}$

0 escopo do Código Comercial de 1850, no entanto, era pouco abrangente, e deixava margens para que companhias estrangeiras aplicassem no Brasil a legislação de seus países de origem. A instituição de uma legislação nacional que regulasse o funcionamento das seguradoras ocorre apenas após a Proclamação da República, quando é promulgado 0 primeiro regulamento de seguros no país com a Lei n 294, de 5 de setembro de 1895; essa legislação, no entanto, regulava apenas 0 setor dos seguros de vida. $\cdot \frac{15}{}$ Com a lei decretada, o governo passou a vigiar de forma mais rígida as companhias; as sociedades de seguro de vida deveriam a partir de então manter todas suas reservas no Brasil, investindo o dinheiro em bens nacionais como imóveis, hipotecas, estradas de ferro, bancos, companhias industriais ou depósitos de longo prazo embancos que operassem no Brasil. $\frac{16}{}$

A motivação por trás dessas medidas era impedir a remessa de lucros para o exterior, acusação comum desde 0 grande boom do capital estrangeiro no Brasil, a partir da década de 1860. Nenhuma companhia de seguro estrangeira poderia funcionar no Brasil sem a obtenção da carta patente de declaração, expedida pelo governo e entregue mediante o depósito de Rs 200:000\$000 no Tesouro Nacional via compra de apólices da dívida pública; o objetivo dessa medida era que o depósito servisse como garantia da sociedade para responder às obrigações contraídas.

A legislação para o setor continuou se aperfeiçoando, e em 10 de dezembro de 1901, sob a administração de Campos Salles e seu Ministro da Fazenda, Joaquim Murtinho, promulgou-se o Decreto $n^{\circ} 4.270$, conhecido como Regulamento Murtinho. $\frac{17}{}$ A nova legislação assemelhava-se à lei de setembro de 1895; mantinha grande parte das propostas desta última, mas ampliava a regulamentação estatal para além de companhias de seguro de vida, incluindo 
seguradoras marítimas e terrestres, nacionais e estrangeiras, já existentes ou que viessem a se organizar no território nacional. Além de ter estendido as normas de fiscalização a todas as seguradoras queoperavam no país, o Regulamento Murtinho criou a Superintendência Geral de Seguros, diretamente subordinada ao Ministério da Fazenda.

Com a criação da Superintendência foram concentradas em uma única repartição especializada todas as questões atinentes à fiscalização de seguros, antes distribuídas entre diferentes órgãos. Sua jurisdição alcançava todo o território nacional e as fiscalizações realizadas poderiam ser preventivas, exercidas após o exame da documentação da sociedade que requeria autorização para funcionar, ou repressivas, sob a forma de inspeção direta e periódica das companhias. Posteriormente, em 12 de dezembro de 1903, através do Decreto n 5.072, a Superintendência Geral de Seguros foi substituída por uma Inspetoria de Seguros, também subordinada ao Ministério da Fazenda. $\frac{18}{2}$

Para regular minimamente a participação das empresas estrangeiras no setor de seguros, o governo promulgou dois decretos que obrigavam a apresentação de pedidos de autorização de funcionamento e aprovação dos estatutos, além de exigir a publicação anual na imprensa dos balanços das companhias autorizadas a funcionar; aos poucos este protocolo também passa a ser exigido para as seguradoras nacionais. Esta nova condição acabaria por estimular um maior acesso à informação econômica das firmas, cujos dados passavam pela primeira vez a circular pela imprensa e permitiam a construção de discursos de autolegitimação ou ataque a companhias concorrentes. ${ }^{\frac{19}{}}$

0 contrato de seguros no Código Civil brasileiro e uma maior capacidade regulatória para o setor, no entanto, viriam apenas em 1916, quando foi sancionada a Lei n 3.071.른 0 s preceitos formulados pelo Código Civil e pelo Código Comercial compunham o chamado Direito Privado do Seguro, cujo principal objetivo era fixar princípios essenciais do contrato e disciplinar os direitos e obrigações das partes. Passava-se então a oficialmente evitar e prevenir conflitos entre os interessados nos contratos, o que muito influenciou o desenvolvimento do setor de seguros no Brasil.

A partir dos novos marcos de legislação propriamente nacionais, temos a construção de um aparato institucional fundamental para o acesso das firmas às informações básicas do próprio setor. Essa mesma legislação, ao exigir as publicações de balanços anuais a respeito do funcionamento das seguradoras, funcionava como um importante indicador de dados econômicos, cujas repercussões podiam ser sentidas no âmbito dos serviços, da produção e da circulação.

\section{Divulgação de informação econômica: os relatos das companhias de seguros nos jornais}

Como dito acima, é a partir de 1903, com a criação da Inspetoria de Seguros subordinada ao Ministério da Fazenda, que se faz obrigatória a publicação de balanços e balancetes de companhias de seguros no Diário Oficial. Consideraremos esta mudança crucial; a partir de agora será sistematizada a publicização de informação econômica de firmas cuja intensa capacidade de mobilização de poupança dava-lhes forte componente estratégico, sobretudo se considerarmos o contexto de pouca financeirização do Brasil de então. Foram mudanças na legislação do setor de seguros que abriram caminho à constituição de um espaço público, a saber, a imprensa, onde a divulgação da informação econômica tornar-se-ia regra.

No que diz respeito à formação de poupança gerada pela atividade seguradora, cabe identificarmos quais as origens desta condição. Sabemos que a manutenção de um equilíbrio entre a arrecadação de prêmios dos segurados e a ocorrência de sinistros permitia às firmas obterem lucros ou prejuízos; na ocorrência sistemática de lucros formavam-se por vezes saldos ociosos capazes de serem mobilizados para distintas operações, dentre as quais citamos a compra de títulos da dívida pública por parte das seguradoras. $\underline{21}^{1}$

Em meio a um contexto de diversificação das atividades das companhias de seguros, cuja forte participação financeira cresce via mobilização de saldos ociosos, a circulação de informação econômica referente aos seus balanços passa a ter um papel cada vez mais relevante, conforme demonstraremos a seguir a partir de casos empíricos. Na ausência de dados 
agregados estatísticos capazes de precificar e estipular riscos, as companhias de seguros inseriam-se no mercado e se posicionavam frente às suas concorrentes via a publicação de informação econômica na imprensa. A divulgação dos dados a respeito das condições de funcionamento das firmas funcionava como um valioso sistema informativo, a partir do qual essas seguradoras relacionavam-se entre si.

Citaremos o caso bastante emblemático do jornal Correio Paulistano, cujas páginas, ao longo de março de 1908, foram espaço de disputa entre as companhias de seguros brasileiras Sul América, Equitativa e Garantia da Amazônia, com a primeira acusando as últimas de pouco confiáveis em suas reservas e poupanças. A Equitativa publicou sucessivos textos com a manchete "Superioridade da Equitativa sobre a Sul América", enquanto esta última se referia ao mau estado das contas da concorrente com o título: “Comparações necessárias!! Verdade às claras!!."2 A rivalidade entre ambas aos poucos se acirrou, e as acusações da Sul América contra a Equitativa passaram a se referir à ausência dos depósitos no Tesouro Federal. Nas palavras da própria publicação:

Não consta na Caixa de Amortização que a Equitativa tenha apólices da dívida pública. Até hoje e apesar de intimidada pelo fiscal de seguros do governo federal, a Equitativa não fez, como é de lei, o depósito de 200 contos em apólices no Thesouro, para poder funcionar, a exemplo de suas congeneres. Para fugir desse depósito legal, ella lança mão de chicanas, allega que a lei não tem effeito retroactivo, diz uma inanidade de cousas, e afinal não entra com o deposito para o Thesouro da República. $\frac{23}{3}$

Continua a Sul América:

Compare-se com a seriedade da Sul América, que possue mais de 6 mil contos em apólices da dívida pública. E a Sul América não fez questão, entrou logo com o depósito de 200 contos para o Thesouro, é este seu acto, além de ser uma obediência à lei, despertou todas as sympathias e a confiança do público em favor da Sul América. A Equitativa prefere questionar, levar mais de 8 annos a gastar o dinheiro dos segurados do que "dar o braço a torcer" perante o público, do que cumprir com uma justa disposição de lei. E si a Equitativa possue apólices da dívida pública, que faça constar isso nos jornaes, nos seus balanços, balanços que há perto de 3 annos os segurados ignoram. Tendo como deve ter um movimento de despeza, diga qual a sua receita? A sua fortuna? Quantos prédios possue? 24

A discussão termina com a Sul América questionando onde a Equitativa teria empregado os valores declarados em seus balanços e, por fim, acusando-a de não possuir os bens que declara na imprensa:

Ninguém sabe onde a Equitativa empregou 3.879:715\$500, contando do seu último balanço, publicado em 1904! Quanto tem empregado em hypotecas de predios? Venha pela imprensa e diga que tem umauma só já satisfaz a curiosidade do publico. Qual! A Equitativa não possue cousa alguma: o seu último balanço, dado em 1904, accusou um saldo de 3.879:715\$500, constante unicamente de um documento de letras descontadas de um banco que falliu e que ainda é liquidante o atual presidente da Equitativa. ${ }^{25}$

Dentre as acusações, consta um apontamento da Sul América a respeito das altas cifras dos salários dos presidentes da Equitativa e a ausência de uma estrutura democrática na composição dos votos dos segurados. Dentre as acusações mais fortes, no entanto, está a afirmativa de que a Equitativa teria subornado a imprensa para que publicasse seus balanços como sustentáveis e superavitários. $\underline{\underline{26}}$

Podemos considerar o referido conflito como uma emblemática disputa entre duas companhias nacionais de porte razoável, ambas preocupadas com o domínio do mercado, com a destruição da concorrência e, acima de tudo, com a construção de uma legitimidade para com o público, característica fundamental para a prosperidade de instituições financeiras. Adjetivos como moralizada, prestigiosa e inatacável, usados pela Sul América para definir a si mesma, bem como referências a valores, dignidade e orgulho, presentes no seu discurso de acusação, são bastante frequentes; por se tratarem de instituições administradoras de dinheiro de terceiros e formadoras de poupanças, considera-se natural 
que em um incipiente mercado de capitais como o brasileiro de então houvesse razoável nível de desconfiança perante os bancos e as companhias de seguros, sua solvência e capacidade de cumprir obrigações.

A relação recíproca entre estatística e realidade tornar-se-ia uma característica fundamental para o funcionamento de firmas seguradoras ao longo do século XX; mesmo antes do estabelecimento desta relação, pode-se considerar os balanços das empresas publicados no Diário Oficial e as formas de cálculo dos contratos de seguros como capazes de revelar mudanças na relação entre economia, cultura e participação das instituições na vida dos sujeitos.

No caso da disputa entre as referidas companhias de seguros, temos exemplo da importância da divulgação e do acesso à informação econômica por parte do público consumidor, mas não apenas; como dito acima, as próprias firmas seguradoras construíam seus discursos e planejavam suas possibilidades de atuação a partir dos dados divulgados nos periódicos da época, tais como o Diário Oficial ou o próprio Correio Paulistano.

A desconfiança e receio por parte do público brasileiro em relação às companhias de seguros, pouco familiarizados com o funcionamento de estruturas financeiras, podem ser constatados por diversos outros casos apresentados na imprensa; citaremos alguns deles. Em setembro de 1905, o Correio Paulistano publicou texto de um leitor denunciando as más condições financeiras da empresa estrangeira New York Insurance Company; a companhia era acusada de realizar operações de empréstimo fictícias, de pagar salários desproporcionais ao presidente e ao corpo administrativo, e de não possuir suficientes reservas para pagamento de sinistros. Dado o "avultuado número de segurados da New York Life Insurance no Brasil", o governo solicitou explicações a Thomas Buckner, vice-presidente da companhia em Nova York. 27 Como resposta vinda da sede nos EUA, a companhia alegava um ativo de mais de 300 milhões de dólares, uma reserva de 47 milhões de dólares, perfeitas condições de funcionamento e total capacidade de solvência; também aproveitava a oportunidade para questionar as reais condições de funcionamento da sua principal concorrente, a Equitable, que supostamente teria sérias dificuldades de administração. $\underline{\underline{28}}$

Além das disputas entre o capital, nacional e estrangeiro, em busca de espaço no emergente mercado de seguros brasileiro, constatamos sucessivos casos de fraudes no setor, a maior parte noticiada pela imprensa.

Em maio de 1889, o jornal The Rio News publicou informações a respeito de uma grande tentativa de fraude envolvendo a carga de mercadorias de um navio, avaliada em cerca de Rs $21.000 \$ 000$. A mercadoria havia saído da região de Penedo, no Sul do estado do Rio de Janeiro, e encaminhava-se em direção ao porto da capital, quando os subscritores e segurados receberam a notícia de que estava sendo planejada a destruição do navio. Os representantes da seguradora, cujo nome não foi revelado na notícia publicada, telegrafaram para o dono do navio a fim de cancelar o seguro; apesar da situação, as contas do carregamento e as letras de câmbio contra o navio puderam ser recebidas e honradas. $\underline{29}$

Anos depois no Rio de Janeiro, em fevereiro de 1904, foi noticiada a existência de um "sindicato" que se propunha a montar diversas casas de secos e molhados, segurando-as por altas somas em diferentes companhias de seguros. Em seguida as casas eram incendiadas e as companhias obrigadas a pagar o valor dos seguros feitos; em outros casos, os armazéns de secos e molhados decretavam falência. $\cdot \frac{30}{}$ No mesmo ano de 1904 encontramos exemplos de publicações nos jornais denunciando o não pagamento de sinistros pelas companhias, como no caso de Alexandre Herculano Guilherme, que entrou com uma ação contra a Companhia de Seguros Lloyd Americano a fim de obter desta última 0 total de Rs 23:000\$000, referente a um seguro feito anos antes.

Um ano mais tarde, em janeiro de 1905, o Correio Paulistano publicou os detalhes do julgamento do negociante Dante Bertuccelli, membro de uma "quadrilha de incendiários" que operou por cerca de um ano e meio no bairro do Brás, em São Paulo. Dante foi considerado responsável pelo incêndio da noite de 23 de junho de 1903, que "destruiu um armazém de secos e molhados na rua Monsenhor Andrade, esquina com a Benjamin de Oliveira"..11

Em março de 1908 o mesmo jornal publicou que "a pacata população de São Paulo" ficou profundamente marcada pelo "caso Cerveira", fraude ocorrida em setembro de 1901 mas julgada e esclarecida sete anos depois: 
Ninguém houve que por elle não se interessasse; São Paulo inteiro commentou-o e devorava as edições das folhas que melhores detalhes encerravam nas suas longas descripções. Francisco Henrique Cerveira, a alma de toda essa mystificação, a cabeça pensante da quadrilha de intelligentes estellionatários, celebrizou-se logo, como era natural. $\underline{\underline{3}}$

O jornal afirmou que Francisco Henrique Cerveira "illudiu com rara habilidade a companhia de seguros Sul América", e logo em seguida engajou-se ao lado de nova quadrilha em um crime contra a companhia Garantia da Amazônia. Após a morte do segurado Manuel Bernardino Gonçalves, a companhia concedeu o pecúlio referente ao seu seguro de vida; depois de concluída a investigação policial, descobriu-se que o referido segurado não estava morto e em seu caixão havia dois sacos de terra. A quadrilha havia se beneficiado do valor do seguro, dando a Manuel uma pequena porcentagem do total. .4

A versão oficial apresentada pelas seguradoras na imprensa frequentemente incluía a desconfiança de fraudes e quadrilhas que forjavam sinistros. Em julho de 1906, as suspeitas recaíram sobre uma fábrica de tabaco do Rio de Janeiro que, após ter sofrido terrível incêndio, reivindicou seu altíssimo seguro de Rs 500:000\$000, valor verossímil para a proteção de estabelecimentos fabris à época. $\frac{35}{5}$ Situações contrárias também ocorriam; quando as seguradoras se recusavam a pagar sinistros a acidentes, a imprensa tendia a noticiar e os casos ganhavam certa notoriedade. $\mathrm{Na}$ edição de 11 agosto de 1909, o Correio Paulistano relatou o processo pelo qual respondiam na Segunda Vara da capital paulista as companhias Integridade e União Commercial dos Varegistas. Após se recusarem a pagar o sinistro de uma fábrica de chapéus incendiada, ambas as companhias sofreram forte pressão da imprensa e tiveram que entregar, cada uma, a quantia de Rs 37:500:000 ao proprietário do estabelecimento. $\frac{36}{}$

Notamos nas páginas do Correio Paulistano a publicação de casos bem-sucedidos, onde clientes das companhias de seguros sentiam-se devidamente contemplados pelas firmas e buscavam o espaço da imprensa para manifestar sua satisfação. A maior parte dos casos são de maridos que morriam e deixavam algum montante às viúvas, cujo recebimento da apólice de seguros de vida após o falecimento do segurado fazia-se de forma integral. Em maio de 1904 o jornal noticia a "boa atitude" da Companhia Sul América ao realizar indenizações de Rs 50:000\$000 a uma viúva. $\cdot \frac{37}{}$

Também em maio de 1904 é relatado na imprensa o falecimento em São Paulo do "estimado corretor desta praça e conceituado capitalista", Alberto José Guignard, deixando à viúva Leonor Veiga Guignard o valor de Rs 200:000\$000, soma considerada pelo próprio jornal como bastante expressiva. ${ }^{38} 0$ referido seguro deixado a Leonor Veiga Guignard despertou, durante todo o mês de maio de 1904, a atenção do Correio Paulistano a respeito da importância dos seguros de vida em uma sociedade onde, pouco a pouco, "desaparecia a força da superstição". .9 Segundo texto publicado no jornal pela companhia Sul América:

O seguro de vida tornou-se hoje uma imposição da previdência, e cada vez mais alarga-se mais a sua esphera de acção em toda a parte do mundo. Todos os factores de resistencia foram pouco a pouco desapparecendo, apesar de repousarem primitivamente numa das forças mais invencíveis da natureza humana, a força da superstição; e hoje o seguro de vida entra triuphalmente, como um indispensável apparelho, nos habitos de toda a sociedade. Não temos sinão louvores para os progressos que elle tem feito no Brasil. Evidentemente podia ser muito maior o seu desenvolvimento: mas, si compararmos a marcha ascendente que ele tem tido neste ultimo deccenio, verificar-se-á que nos sobram motivos de contentamento. Uma causa principalmente, tem concorrido para isso, e é a seriedade provada das nossas companhias: de facto, raras tem sido as questões sobre pagamento dos sinistros, e em regra a liquidação é feita com a maior presteza e a maior solicitude. .0

Há também uma reflexão acerca do papel das companhias de seguros como instituições capazes de substituir o Estado no que diz respeito à formação de caixas de previdência:

Não há dúvida que as companhias de seguros estão destinadas a substituir o Estado nas pensões e montes-pios. Não se trata de uma questão a discutir, porque é um caso resolvido: não haveria orçamento capaz 
de supportar a progressão das despesas com a chamada classe dos inactivos. O que se vai dar, mesmo nos países onde permaneceram as pensões e os montes pios, é a adaptação dessas instituições de seguro, entrando como factores indispensaveis a edade, as prestações, a capitalização, as reservas. De resto se isso não quer ceder, será uma simples ilusão para o Estado e ainda pior para os contribuintes: a catastrophe final é inevitável. $\underline{\text { I1 }}$

0 mesmo texto, mais adiante, compara as circunstâncias do mercado de seguros brasileiro aos EUA e países europeus, os quais, segundo o Correio Paulistano, possuíam ampla tradição em seguros de vida e faziam-no nas mais variadas situações:

Devíamos ir pensando um pouco neste problema, aliás já tão bem estudado entre nós. E quanto ao seguro de vida, que hoje é feito nos EUA e na Europa até em pequenas viagens em caminhos de ferro, até para pequenos acidentes de trabalho, toda a propaganda é pouca para generalisal-o, tanto são os benefícios que delle resultam. $\underline{\underline{4}}$

Em fevereiro de 1905 a companhia Sul América utilizou-se das páginas do Correio Paulistano para fazer propaganda de seus sorteios semestrais de apólices de seguros de vida gratuitas; um dos sorteios havia sido organizado como um grande evento na sede da companhia no Rio de Janeiro, sorteando 45 títulos no Brasil, Chile e na Argentina. A partir do trecho publicado no Correio Paulistano constatamos a preocupação da firma em se posicionar como uma seguradora mais "humana" que suas concorrentes:

Eleva-se a Rs 8:000\$000 aproximadamente a somma paga pela Sul América às viúvas e orphams de seus segurados fallecidos, sem que uma só vez fosse necessaria a intervenção judicial para a liquidação dos seguros. A única família onde os chefes de família devem confiar o futuro dos que lhe são caros é a Sul América. $\underline{43}$

Sabemos que a filantropia por meio de sorteios era fundamental para o lucro e bom funcionamento de muitas companhias, pois a concessão dos seguros de vida gratuitos pressupunha a compra anterior de alguma outra apólice e estimulava a permanência na instituição. Os trechos transcritos chamam atenção, no entanto, pela alusão à valores burgueses pouco condizentes com a estrutura política e econômica do Brasil de então, como preocupação com o futuro, poupança e sacrifício, todos conceitos recém introduzidos em uma sociedade cujas heranças escravistas e coloniais faziam-se bastante visíveis. Os referidos sorteios, no entanto, foram suspensos em dezembro de 1906.44

Conforme a presença das companhias de seguros estrangeiras no Brasil tornava-se mais intensa, crescia também a insatisfação das firmas nacionais, incomodadas com o aumento da concorrência. Constatamos facilmente essa insatisfação a partir da leitura da imprensa à época; a pressão por parte das companhias nacionais contra suas concorrentes agrava-se partir de 1906, momento em que a boa condição do café e da borracha no mercado externo geraram estabilidade cambial e atraíram fortemente a presença do capital estrangeiro para o Brasil. ${ }^{45}$ Muitas se manifestaram na imprensa de forma veemente, como a Companhia Vigilancia, que publicou em seu relatório de 1891 o seguinte texto:

As companhias nacionais continuam assoberbadas pela concurrencia de agencias das companhias estrangeiras, e nada teríamos a oppor a essa liberdade, si, niveladas quanto a direitos, também estivessem a nós equiparadas a deveres. Infelizmente, assim não succede, e dessa desigualdade emanam taes inconvenientes, que chegam a fallar ao patriotismo do poder publico, pedindo a sua intervenção nesse grave e momentoso assunpto. $\underline{46}$

Já nos referimos às companhias de seguros como importantes instituições cujo funcionamento permitiu a contínua precaução ao risco por parte das firmas brasileiras no final do século XIX e início do XX. A garantia ao transporte de mercadorias e a acidentes no maquinário de fábricas, por exemplo, proporcionaram maiores possibilidades de acumu- 
lação de capital, já que os custos de transação se reduziam e os ganhos de produtividade aumentavam. A existência de uma rede de proteção capaz de garantir a ocorrência de sinistros serviu de estímulo ao investimento e à construção de novos negócios; é a partir desse cenário que podemos afirmar a importância das companhias de seguros para a aceleração do processo de formação do capital industrial brasileiro. Ao diminuírem as possibilidades de acidentes e prejuízos, as firmas seguradoras estimulavam o investimento e as tomadas de riscos por parte das manufaturas nacionais, em especial ascensão desde a década de 1890.

\section{Conclusão}

Concluímos o presente trabalho afirmando a importância da divulgação e circulação de informação econômica para o funcionamento das companhias de seguros no final do século XIX e início do XX. Através de alguns exemplos empíricos, pudemos comprovar o quanto estas firmas valeram-se da publicação de seus próprios dados para estabelecerem relações de confiança e legitimidade com o público local. Se atualmente o conhecimento estatístico está na base do funcionamento das seguradoras, cujas análises e precificações de riscos são feitas a partir de sofisticadas bases de dados e variáveis, bem como pela interação delas, em outros momentos a sobrevivência destas empresas fazia-se sobretudo pela construção de uma autoimagem de confiabilidade. 0 processo de construção dessa imagem fez-se através dos mecanismos disponíveis, tais como a utilização do espaço público da imprensa para divulgação de bons resultados próprios ou maus resultados de concorrentes. A publicação de fraudes no setor também compunha 0 rol de dados aos quais as firmas e o público poderiam ter acesso, e, desse modo, tomar suas próprias decisões econômicas. Podemos concluir que a emergência de instituições se relaciona de maneira estreita à expansão da técnica, ao conhecimento estatístico e à capacidade de circulação de informações econômicas.

\section{Notas e referências bibliográficas}

Beatriz Duarte Lanna é historiadora e mestre em história pela Universidade de São Paulo, e atualmente doutoranda no Programa de Desenvolvimento Econômico da Universidade Estadual de Campinas. Email: bduartelanna@gmail.com

1 CAMARGO, Alexandre de Paiva Rio, Estatística e política de população no Brasil (1870-1930): notas de pesquisa. Estatística e Sociedade, n. 3, dez. 2013, p. 92.

2 MILLER, Peter, Governing by numbers: why calculative practices matter. Social Research, vol. 68, n.2, 2001.

3 WAGA, Augusto, JUNIOR, Tadeu Henriques, Da Economentabilidade à governamentalização da economia: uma análise dos mecanismos de quantificação das companhias seguradoras. In: Anais do $42^{\circ}$ Encontro Anual da ANPOCS, 2018, Caxambu.

$4 \quad$ Idem, p. 12

5 EWALD, Insurance and Risk. In: BURCHELL, G. et al. (eds.) The Foucault Effect: studies in governmentability. Chicago: The Univesity of Chicago Press, 1992, p. 199.

6 WAGA \& JUNIOR, 2018, op. cit., p. 10

7 NORTH, Douglass \& THOMAS, Robert Paul "An economic theory of the growth of the Western World". Economic history review. Volume XXII, n. 1, 1970.

8 NORTH, Douglass \& THOMAS, Robert Paul, The rise of the Western World: a new Economic History. Cambridge: Cambridge University Press, 1973, p. 06

9 NORTH, Douglass, Institutions, institutional change and economic performance. Cambridge: Cambridge University Press, 1990, p. 03.

10 COSTA, Fernando Nogueira, Brasil dos Bancos. São Paulo: Edusp, 2012. p. 406.

11 Idem, p. 407

12 CASTRO, Ana Célia, As empresas estrangeiras no Brasil, 1860-1913, Rio de Janeiro: Zahar Editores, 1979, p. 71

13 ALVIM, Pedro, Política brasileira de seguros. São Paulo: Ed. Manuais Técnicos de Seguros, 1980

14 COSTA, Ricardo Cesar Rocha da. "A atividade de seguros nas primeiras décadas da República". ALBERTI, Verena (coord.). Entre a solidariedade e o risco: história do seguro privado no Brasil. Rio de Janeiro: FGV-RJ e Funenseg, 2001, p.24

15 BRASIL, Decreto nº 29405 de setembro de 1895, Actos do Poder Legislativo, Rio de Janeiro, 1895, p. 17. 
BRASIL, Actos do poder legislativo, 1895, p. 17.

17 BRASIL, Diário Oficial da União, 10 de dezembro de 1901, p. 02.

18 BRASIL, Relatório do Ministério da Fazenda, 1903, p. 111.

19 COSTA, 2012, op. cit., p. 26

20 BRASIL, Diário Oficial da União, 02 de janeiro de 1916.

21 BRASIL, Actos do poder executivo, 1895, p. 565.

22 BRASIL, Correio Paulistano, Arquivo Público do Estado de São Paulo, 04 de março de 1908, p. 03

23 BRASIL, Correio Paulistano, Arquivo Público do Estado de São Paulo, 12 de março de 1908, p. 06.

24 Idem, p. 06

25 Idem, p. 06

26 Idem, p. 06

27 BRASIL, Correio Paulistano, Arquivo Público do Estado de São Paulo, 17 de setembro de 1905, p. 04

28 Idem, p. 04

29 BRASIL, The Rio News, Rio de Janeiro: A. J. Lamoureux, 27 de maio de 1889, p. 02

30 BRASIL, Correio Paulistano, Arquivo Público do Estado de São Paulo ,22 de fevereiro de 1904, p. 02

31 BRASIL, Correio Paulistano, Arquivo Público do Estado de São Paulo, 14 de janeiro de 1905, p.02

32 BRASIL, Correio Paulistano, Arquivo Público do Estado de São Paulo, 27 de março de 1908, p. 02

33 Idem, p. 02

34 Idem, p. 02

35 BRASIL, Correio Paulistano, Arquivo Público do Estado de São Paulo 03 de julho de 1906, p. 05

36 BRASIL, Correio Paulistano, Arquivo Público do Estado de São Paulo 11 de agosto de 1909, p. 04

37 BRASIL, Correio Paulistano, Arquivo do Estado de São Paulo, 01 de maio de 1904, p. 03.

38 Idem, p. 01

39 A respeito da superstição existente em torno da compra de seguros de vida, considerados portadores de mau agouro para o proprietário da apólice, sabemos que conforme avançavam as décadas de 1890, 1900 e 1910 estes passam a ser mais bem aceitos pela sociedade. Em 1889 o suicídio de um rapaz jovem e membro da tradicional família Teixeira Leite chocou a sociedade carioca da época; o ocorrido foi associado ao fato da vida do rapaz estar segurada pela New York Life Insurance Company. BRASIL, The Rio News. Rio de Janeiro: A. J. Lamoureux ,16 de dezembro de 1889, p. 6.

40 BRASIL, Correio Paulistano, Arquivo do Estado de São Paulo, 26 de março de 1904, p. 02

41 Idem, p. 02

42 Idem, p. 02.

43 BRASIL, Correio Paulistano, Arquivo Público do Estado de São Paulo, 22 de fevereiro de 1905, p. 03.

44 BRASIL, Correio Paulistano, Arquivo Público do Estado de São Paulo, 14 de dezembro de 1906, p. 02.

45 FRITSCH, Winston. “Apogeu e crise na Primeira República: 1900-1930". Marcelo de Paiva Abreu (org.). A ordem do progresso. Dois séculos de política econômica no Brasil. Rio de Janeiro: Editora Campus, 1995, p. 40. Segundo o autor, o período compreendido entre 1900 e 1913 no Brasil pode ser considerado como uma "década de ouro"; a economia brasileira viveu um longo ciclo de crescimento com endividamento, as taxas do produto agregado passaram a ser de $4 \%$ ao ano e a indústria local conheceu um expressivo aumento na sua formação de capital. 0 país também contava com boa recepção do café no mercado externo, e até 1910 os preços da borracha cresciam, tornando a balança de pagamentos superavitária.

46 BRASIL, Relatório do Ministério da Fazenda, 1901, p. 282.

[Artigo recebido em Janeiro de 2019. Aceito para publicação em Dezembro de 2019] 